\title{
اهمية استخدام التقنيات الحديثة لانتاج اعلان بتصميم جرافيكى تفاعلي (مثال تطبيقى على اعلانات الطرق Outdoors)"
}

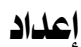

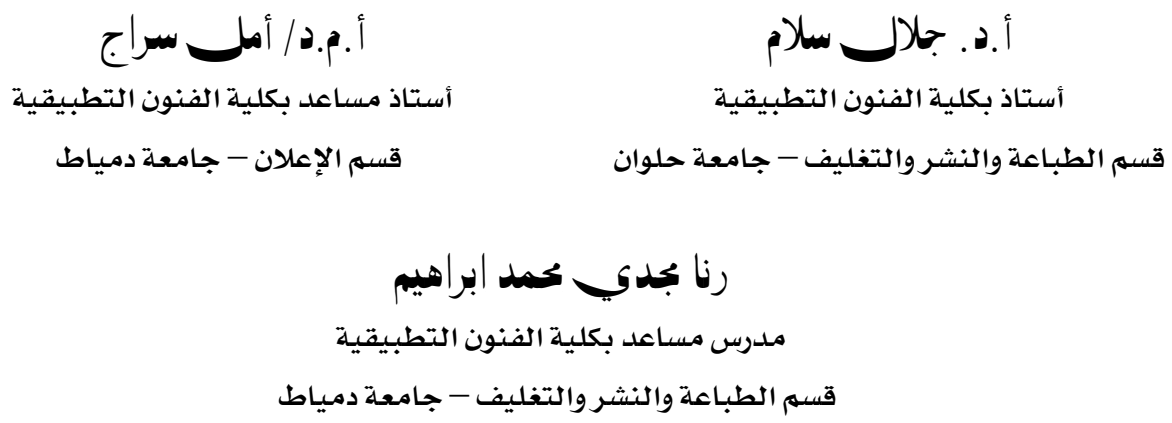




\section{اهمية استخدام التقنيات الهديثة لانتاج اعلان بتصسيم جرافيكى}

\section{تفاعاعي (هثال تطبيقى على اعلانات الطرق Outdoors)}

$$
\text { جلال سلام ا }
$$

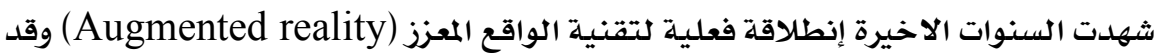
ارتبط ظهورها بنشأة الواقع الافتراضي(Virtual Reality) فما الواقع المعزز الإنة امتداد للواقع

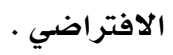

وكان الواقع المعزز (Augmented reality) من اهم التقنيات التى تدمج التقنية بمجال

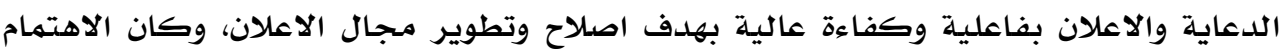

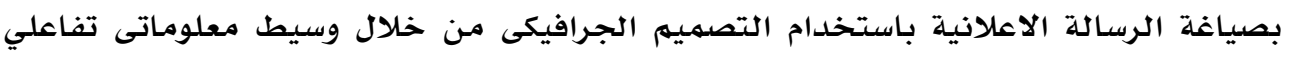

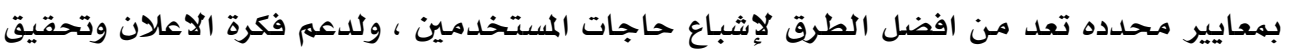

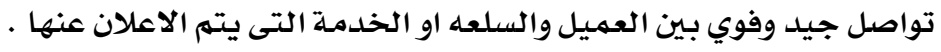

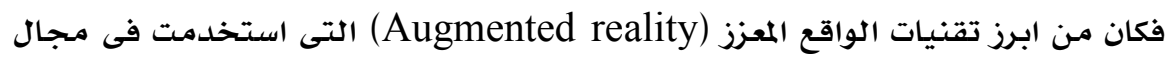
الدعاية والاعلان (Qr-Code) والشاشات التفاعلية التى استخدمت البرامـج التقنية التى تدعم الناحية التفاعلية بين والتانين المستخدم والاعلان والمنتج مثل برنامج (Layar) و برنامـج (Augment) وبرنامج (Po-motion)

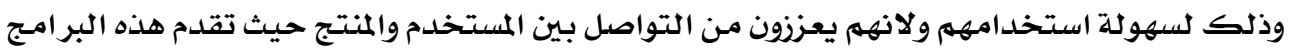

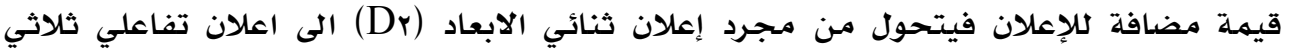

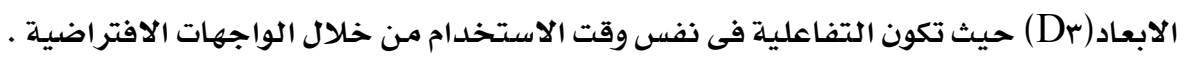

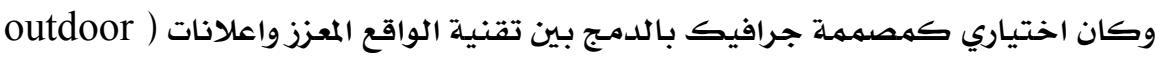

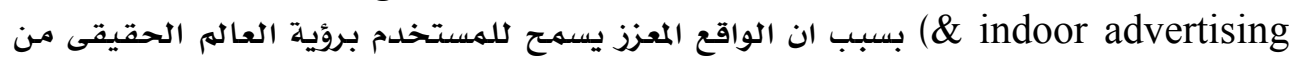
حوله. وتوفر هذه التقنية احساس قوي بالتواصل بين العميل والمنتجج ومعلومات واضحة ودقيقة مـع امكانية التفاعل فى ادخال بيانات واستخراجها بطريقة سهلة وفيلة وفعالة .

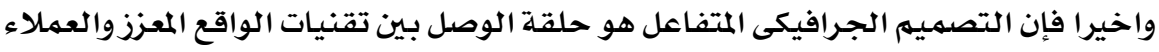

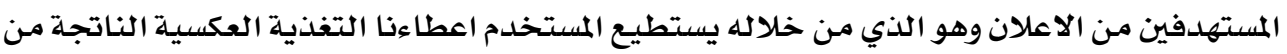


تفاعله مـع الاعلان وهذه التغذية تمكننا من التطوير والتحسين فى الناحية التفاعلية ،كما ترشدنا

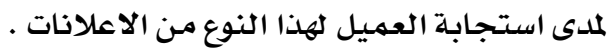

مقدهمة

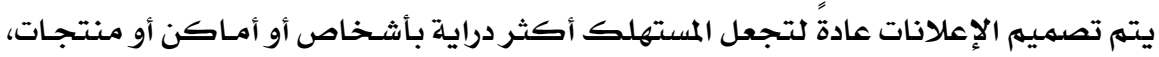

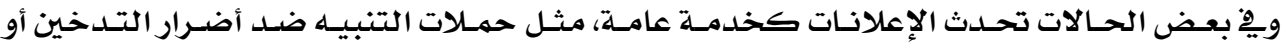

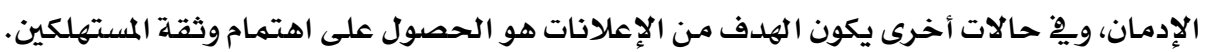

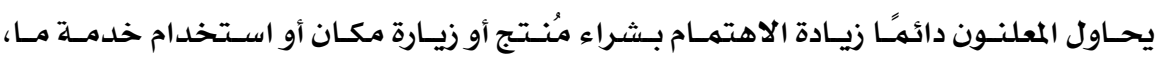

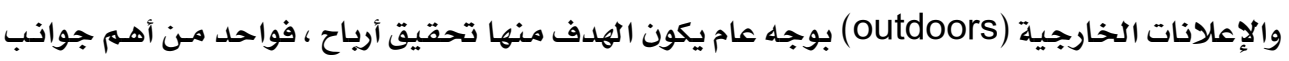

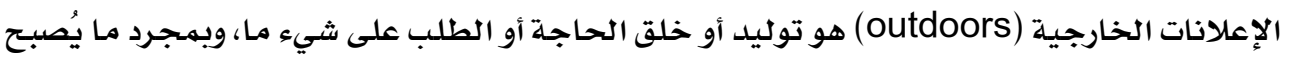

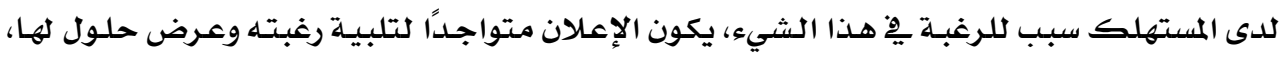

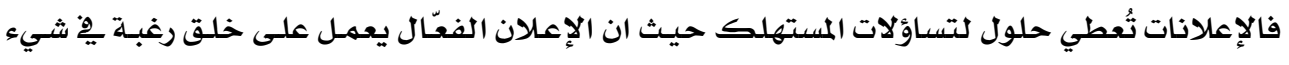

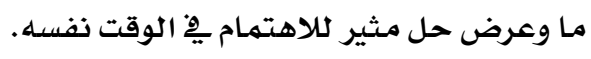

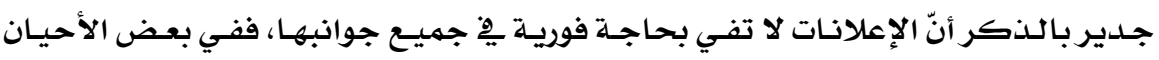

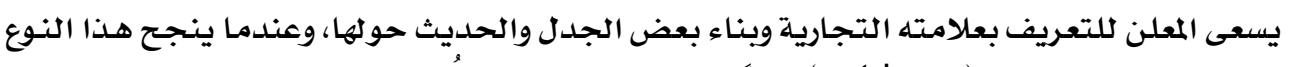

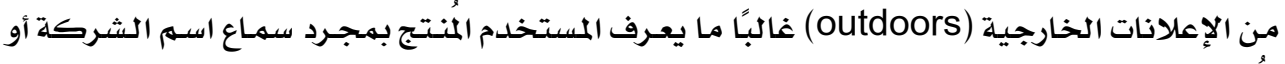
المُنتج نفسـه، ويُكوّن انطباع جيد الاعلات عنها. ونتيجة لتطور الاعلانات بشكل كبير جدا ومحاولة تميز كل شـركة عن مثيلاتها ظهرت

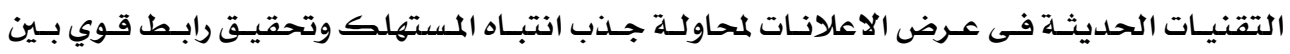
الشركة والمستهلك. مشكلة البحث • قلة الوعي باهمية التقنيات الحديثة لانتاج اعلان تفـاعلي يعتمـد على اسس ومبادئ التصميم

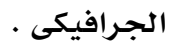

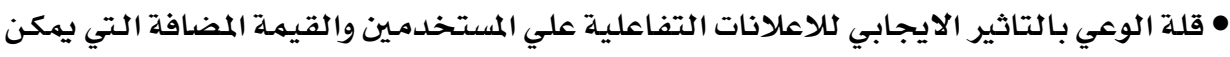

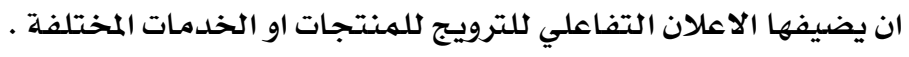

• تفعيل دور التقنيات الحديثة فى انتاج الاعلانات التفاعلية خاصة الاعلانات الخارجية (اعلانات

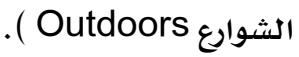
• تحقيق الارتباط بين المستخدم والاعلان التفاعلي باستخدام اساليب الترويج المختلفة .

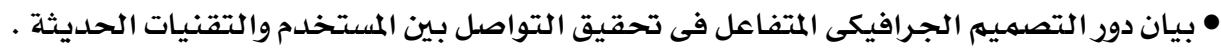




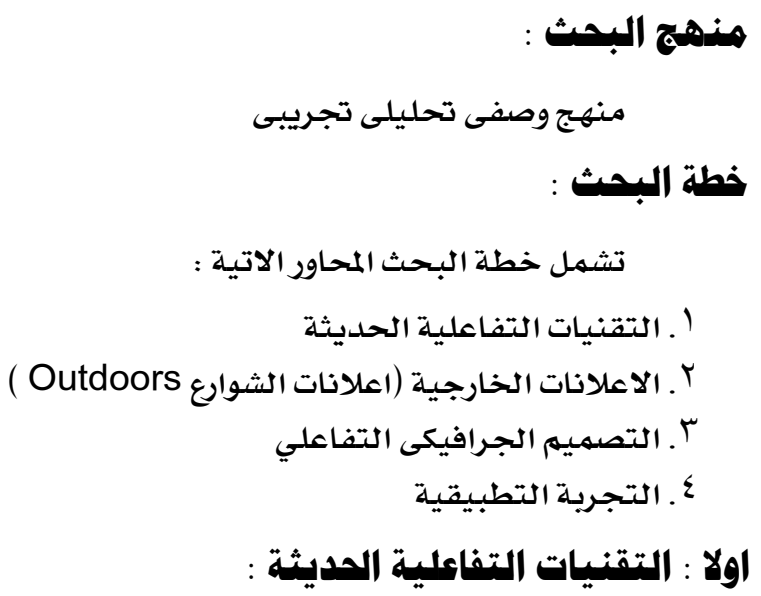

وسـنتناول فى هـذا البـحـث تقنيـة مـن اهـم التقنيـات التفاعليـة الحديثـه وهى تقنيـة الواقـع

المعزز (Augmented reality)

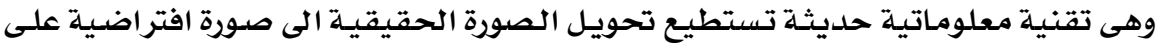

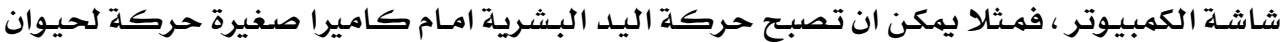

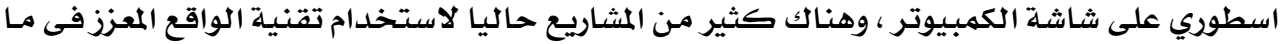

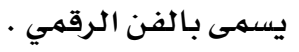

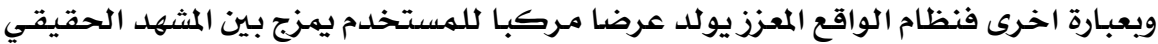

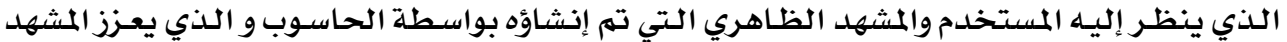
الحقيقي بهعلومات إضافيـة.

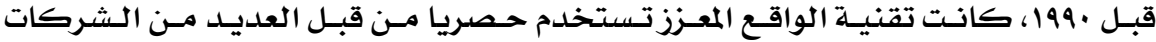

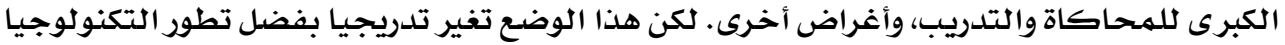

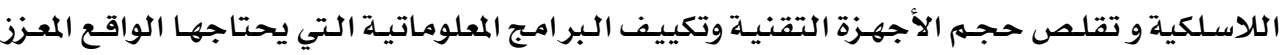

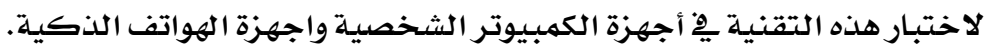

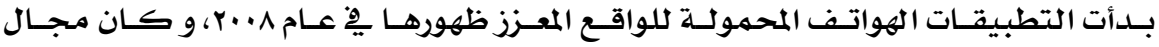

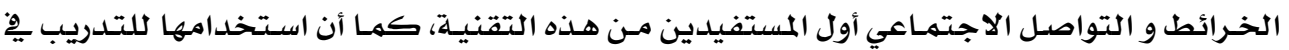

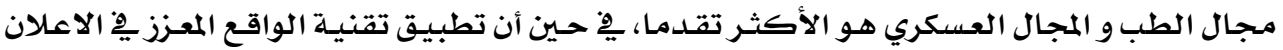
مازال ِِِ بدايته. الاجهزة والتطبيقات التى تلعم تكنولوجيا الواقع المعزز (Augmented reality ) :

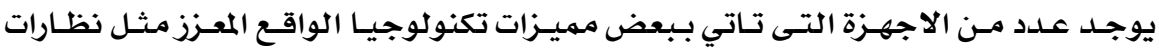

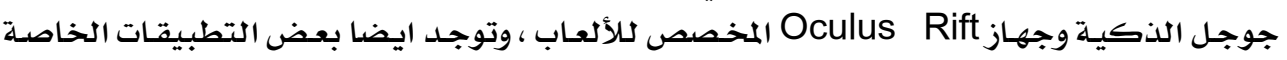


بـالهواتف الذكيـة والاجهـزة اللوحيــة المحمولــة التـى تمكنــك مـن الاسـتفـادة مـن بعـض مميـزات تكنولوجيا الواقع المعزز فعلى سبيل المثثال :

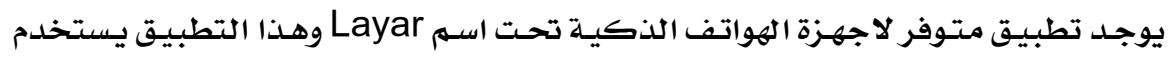

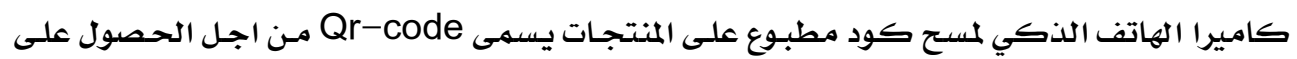

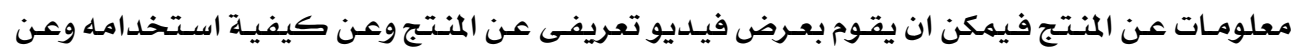

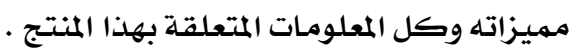
من التطبيقات او البرامج التى تستخلم تكنولوجيا الواقع المعزز :

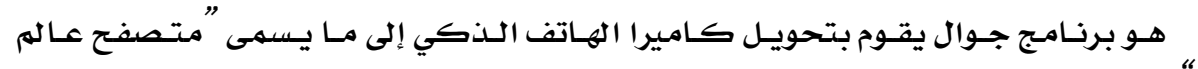

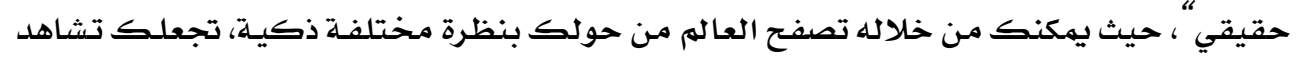

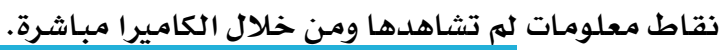

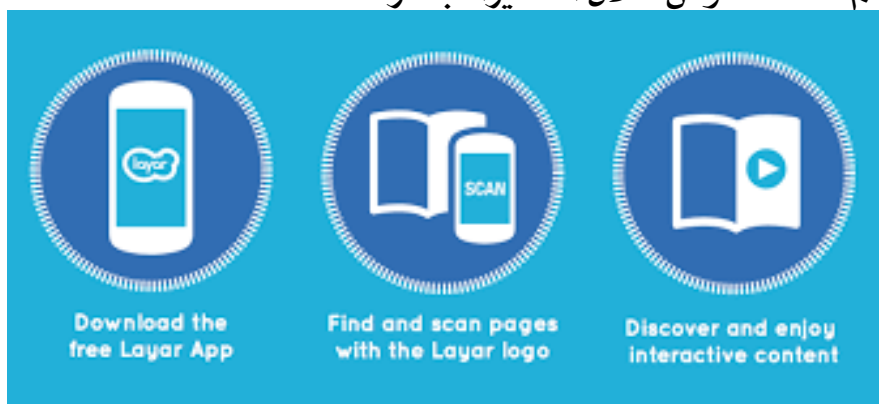

شكل (1) يمثل برنامج layar وكيفية استخدامه

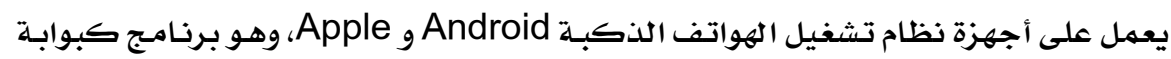

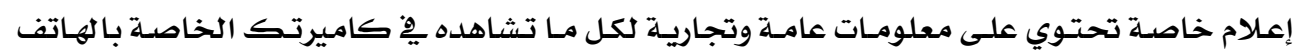

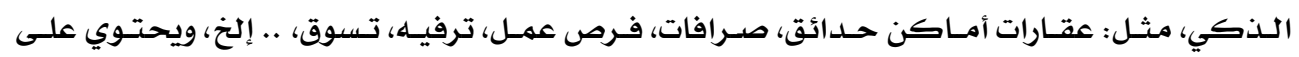

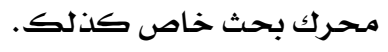

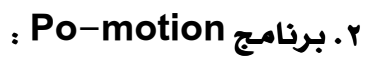

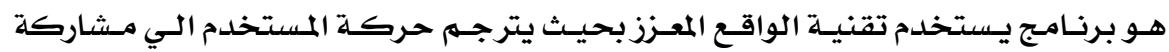

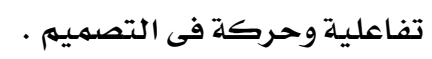

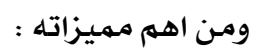

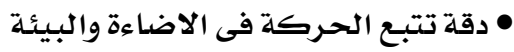

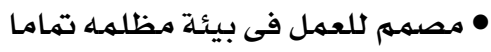

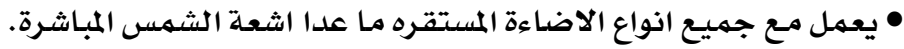

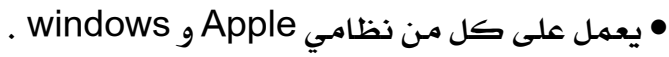




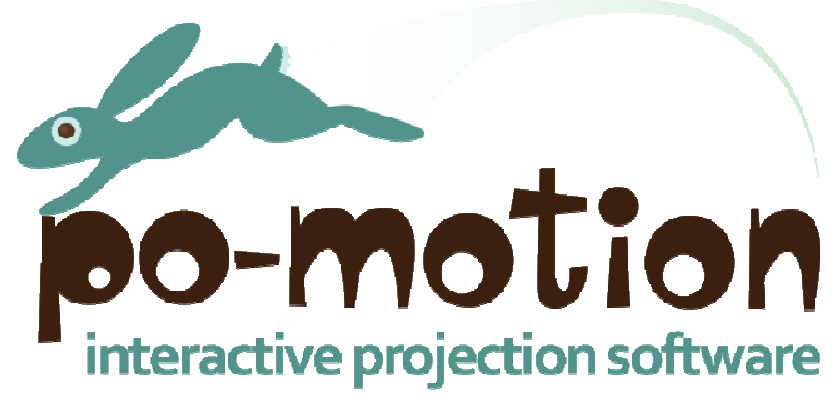

$$
\text { po-motion شكل (r) يمثل برنامج }
$$

كيفية عمل تقنية الواقع المعزز :

تعتمد تقنية الواقع المعزز على تعرف النظام على ربط معالم مـن الواقِع الحقيقي بالعنصـر

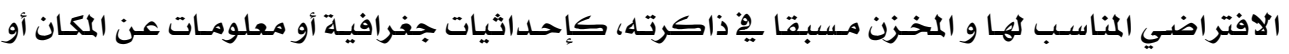

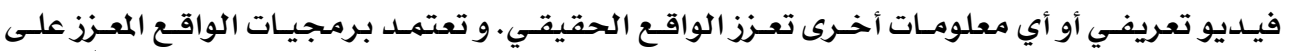

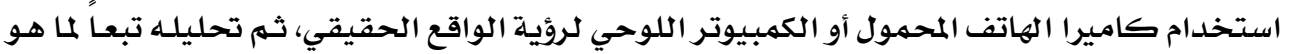

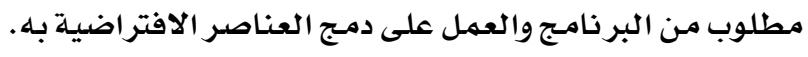
ونشير إلى أنه هناك طريقتان لعمل الواقع المعزز. ففي حين تعتمد الطريقة الأولى استخدام

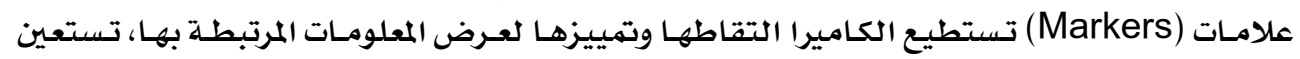

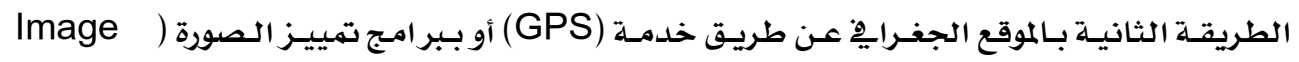
Recognition

\section{ثانيا : الاعلانات الفارجية (اعلانات الشوارع Outdoors ):}

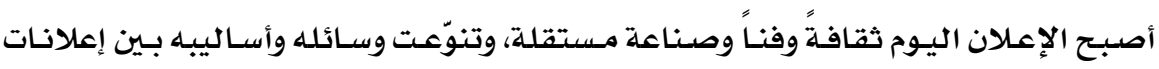

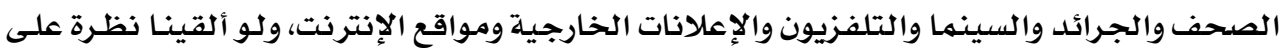

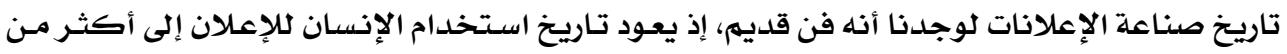

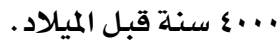

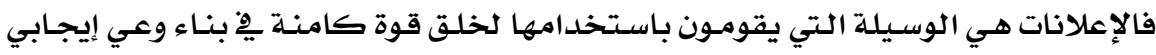

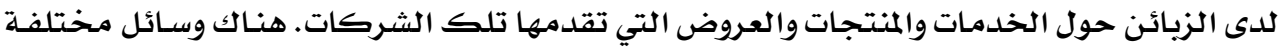

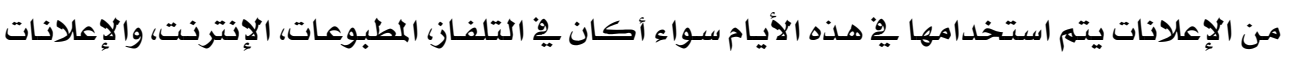

الخارجية (Outdoors).

تلك الأنواع من الإعلانات يتم استخدامها بنـاءً على أسس محسددة وفقـا لطبيعـة الجمهور

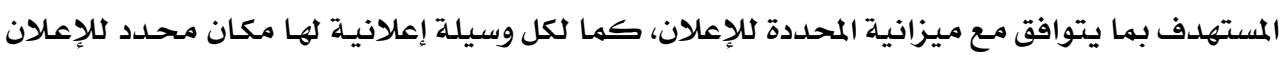

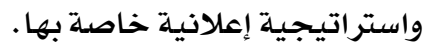




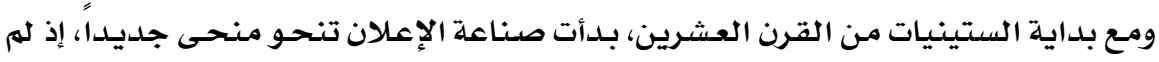

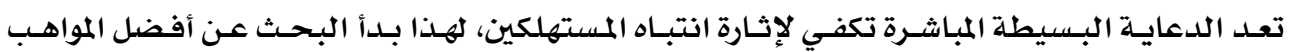

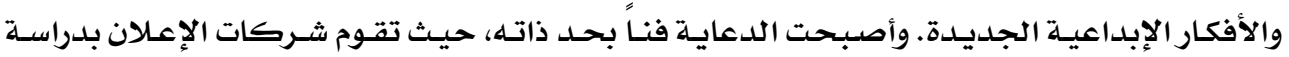

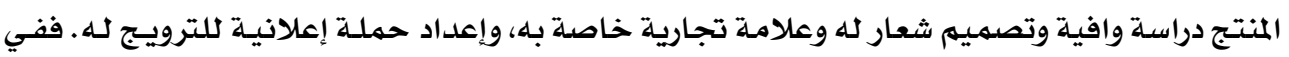

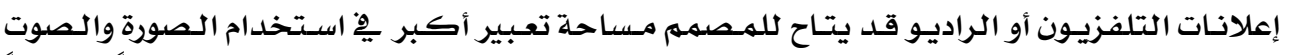

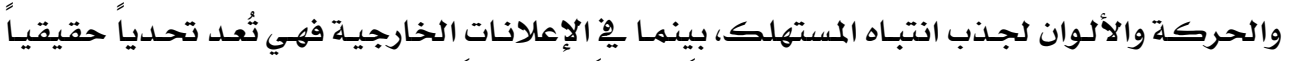

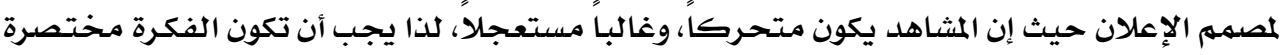

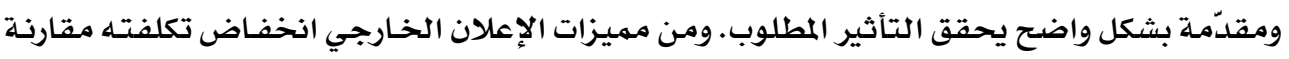

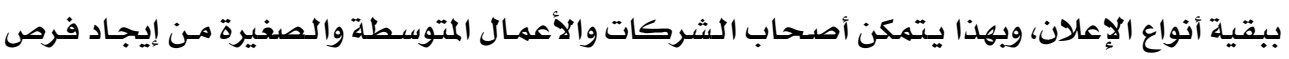
كلإعلان من دون تكاليف باهظة.

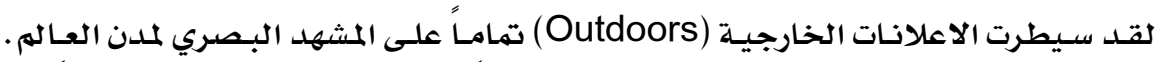

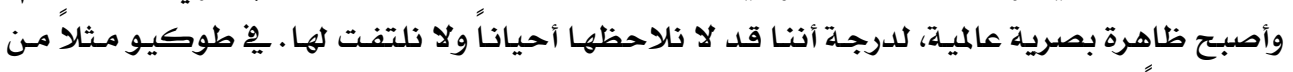

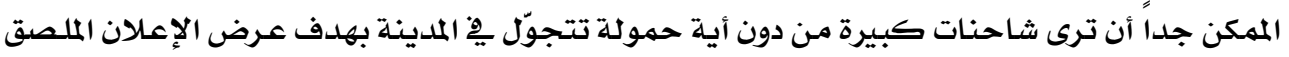

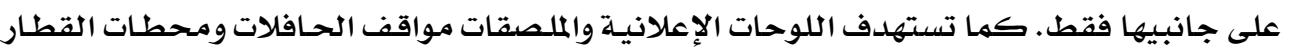

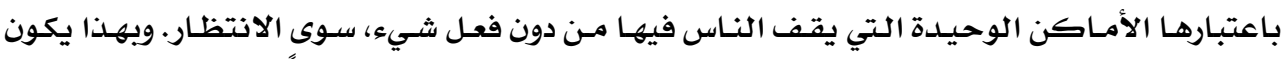

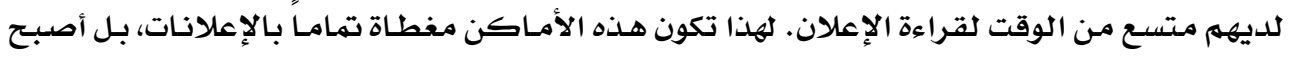
الإعلان يمثل شخصية بصرية لهذه الأماكن.

\section{الاعتبارات والشروط الواجب توافرها في اللوحة الاعلانية : لإندان}

يجب أن يتوافر ٍِِ اللوحة الإعلانية عدة شروط لتتمكن مـن إيصال رسـالتها للمتلقي. فهي

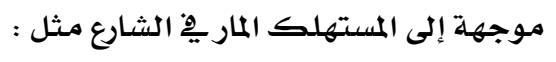

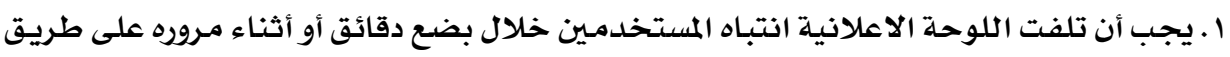

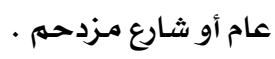

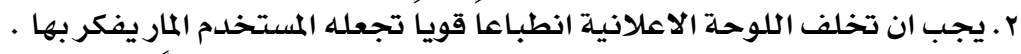

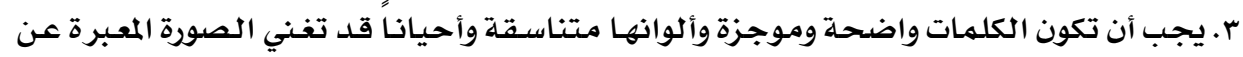

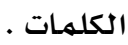

ع ـ يجب أن يراعى اختيار مكان اللوحة على الطريق، فلا توضع يِ اتجاه معاكس للمـرور، واحيانا

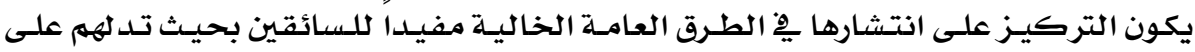

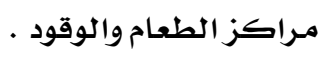

\section{التقنيات المستخدمة في الإعلانات الخارجية وتأثيراتها:}

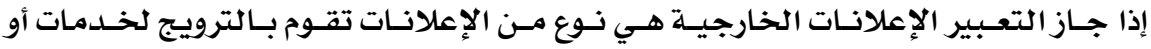

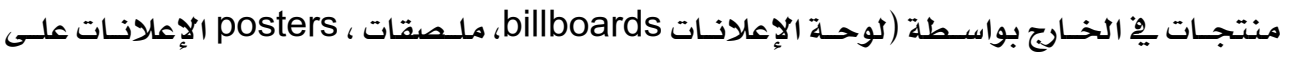




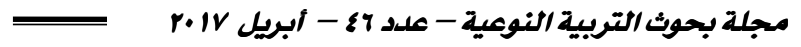

وسائل النقل vehicles، وأماكن انتظار مواقف الباصات ،

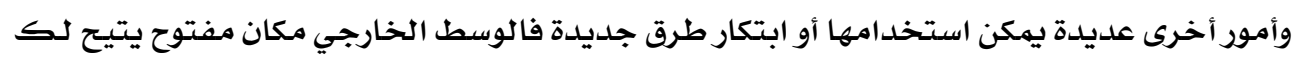

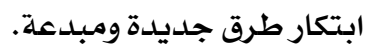

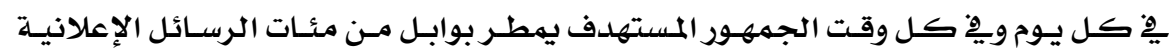

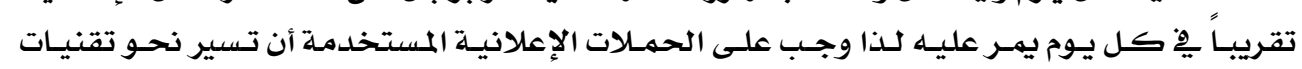

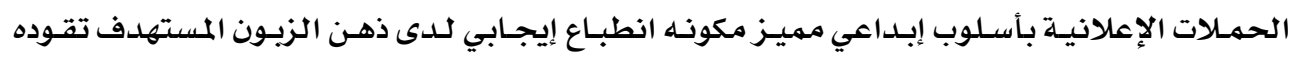

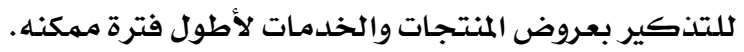

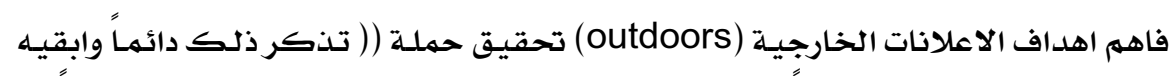

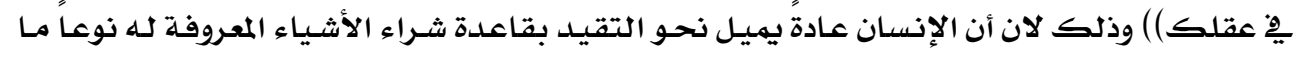

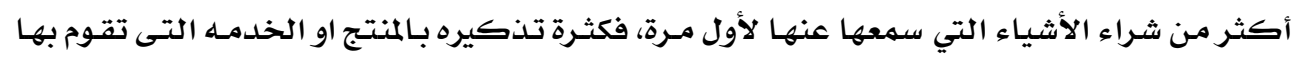

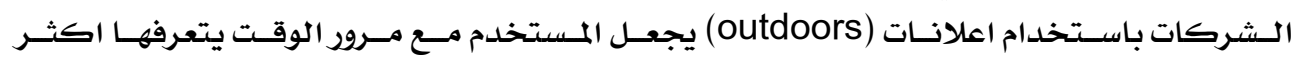

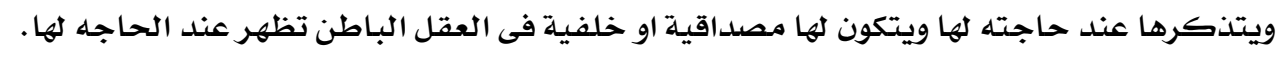

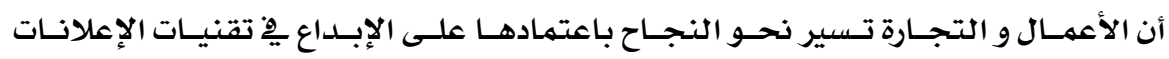

الخارجية.

والآن سنذكر أبرز الطرق المستخدمة ِِ الإعلانات الخارجية:

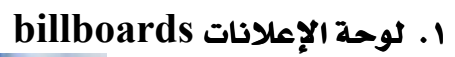

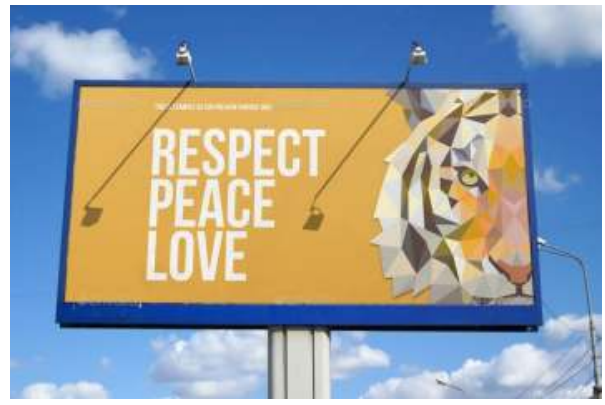

شكل (r) لوحة billboards

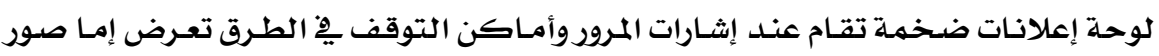

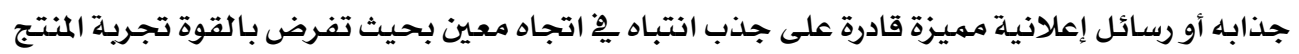
المعلن عنه ولو لمرة واحدة.

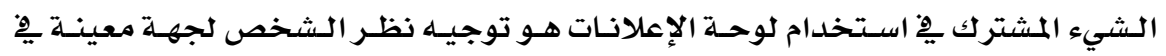

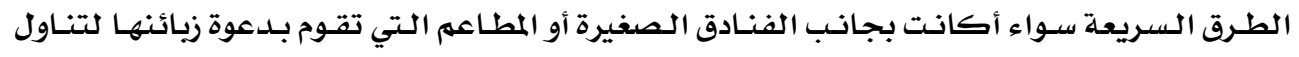
وجبة لديها . 


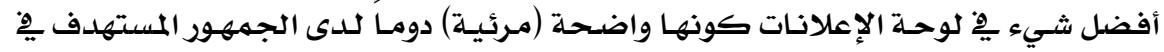

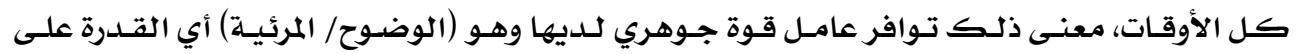

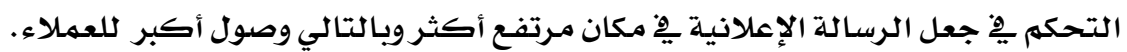

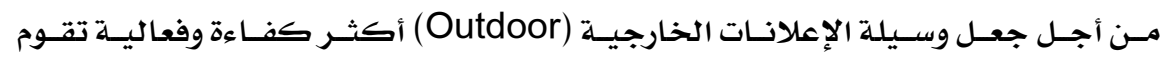

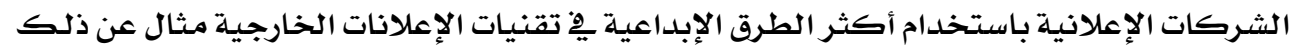

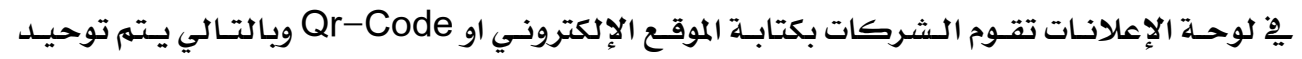

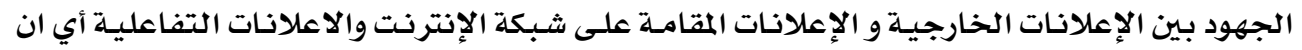

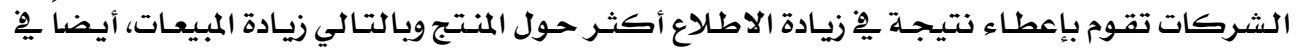

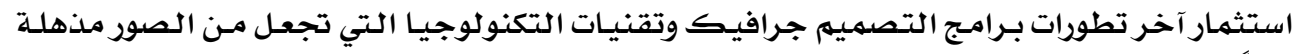

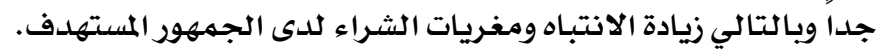

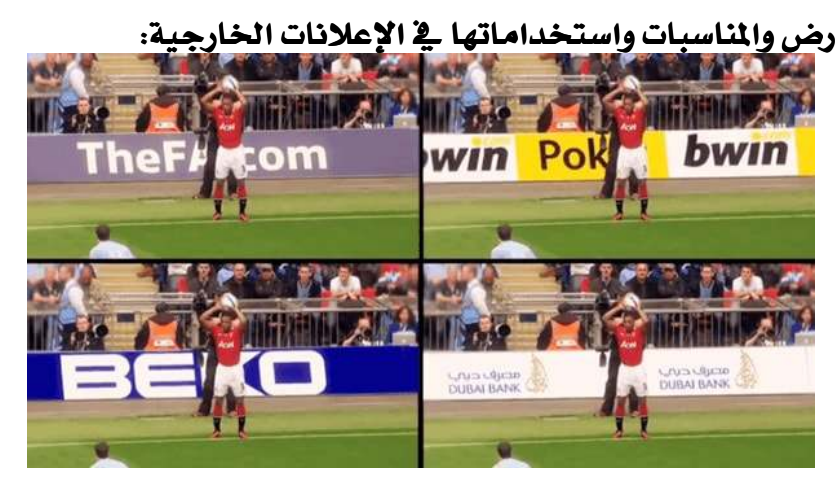

شكل (ع) يمثل اعلانات الاحداث والمناسبات

الكثير من الشركات تشارك بِّ المعارض أو تقوم برعاية الأحداث والمناسبـات وذلك لتحقيق

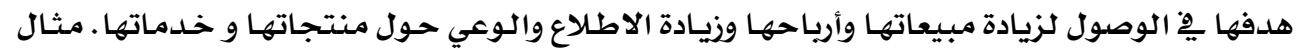

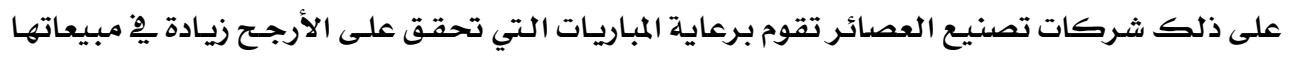

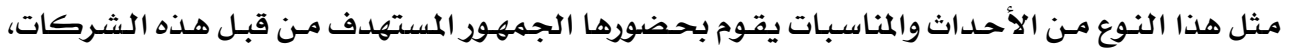

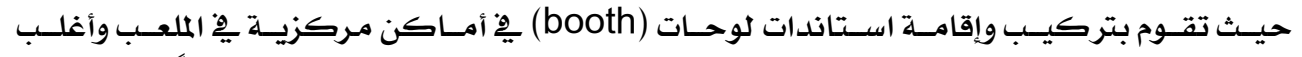

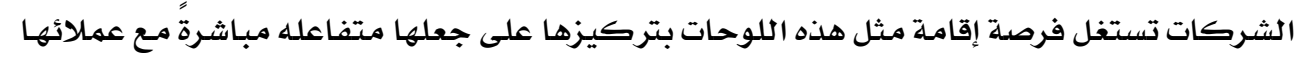

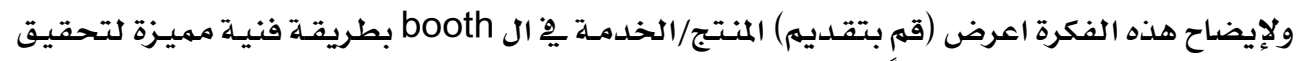

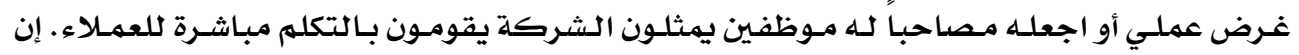

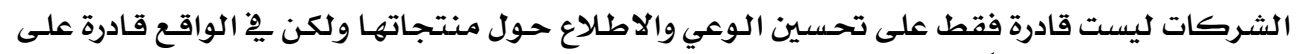

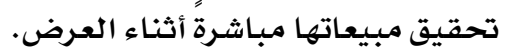


r. r. وسائل النقل وكيفية توصيل الرسالة الإعلانية:
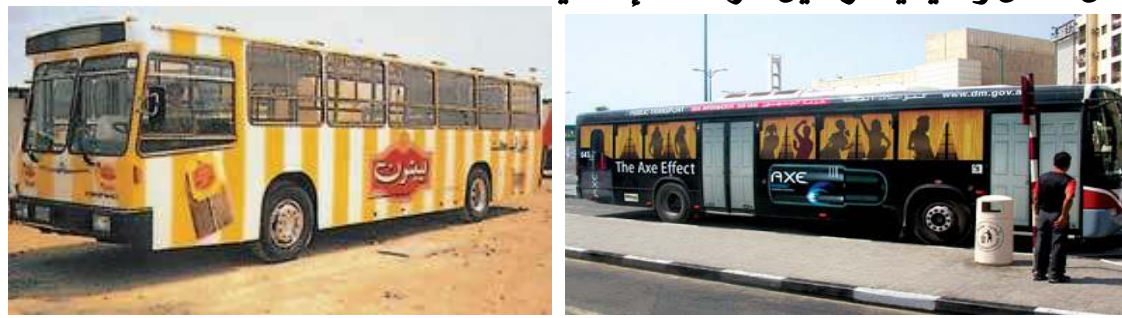

$$
\text { شكل (ه) يمثل الاعلانات على وسعائل النقل }
$$

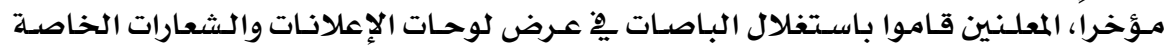

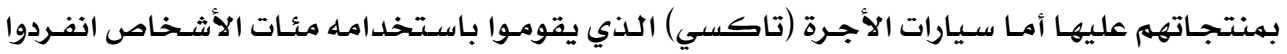

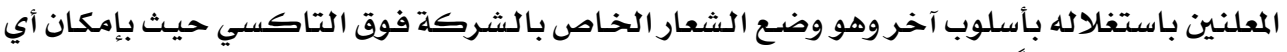

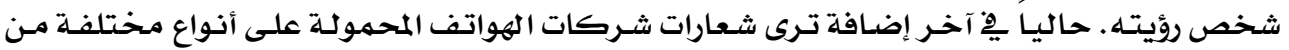

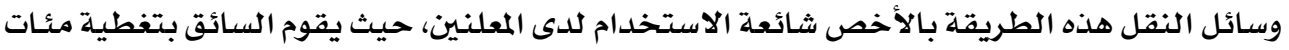

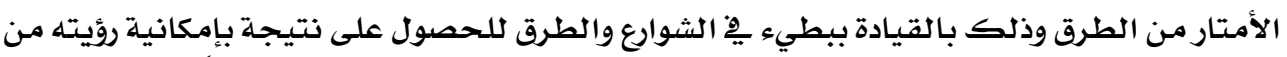

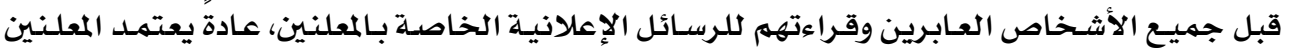

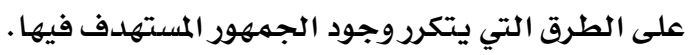
اشكال اللوحات الاعلانية الخارجية (Outdoors) :

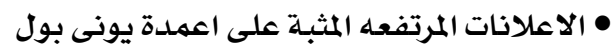

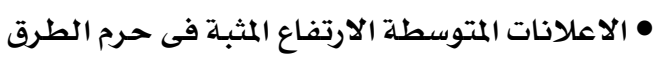

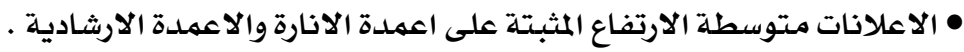

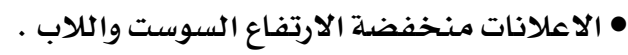

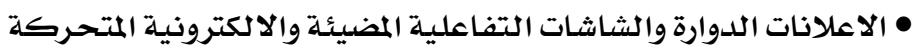

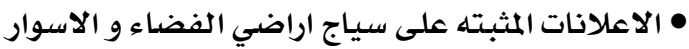

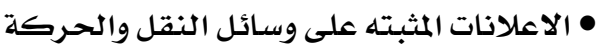

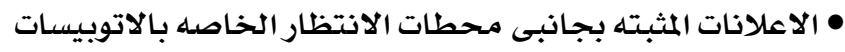

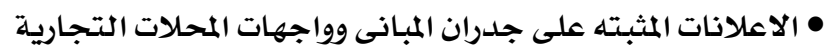
ثالثا : التصميـم البرافيكى التفاعلي :

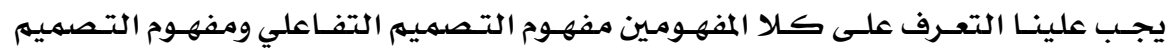
الجرافيكى المتفاعل . 


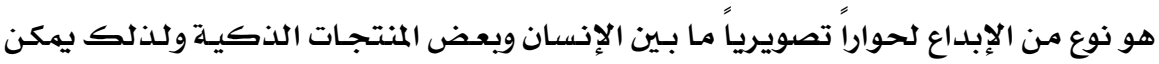

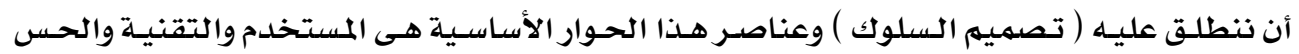

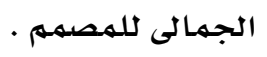

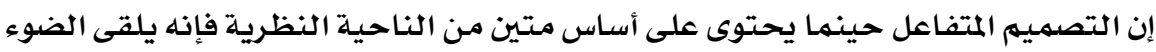

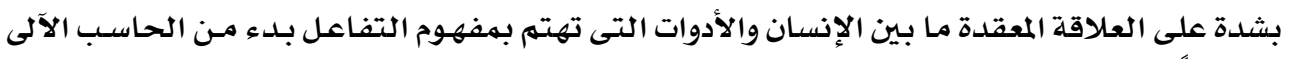

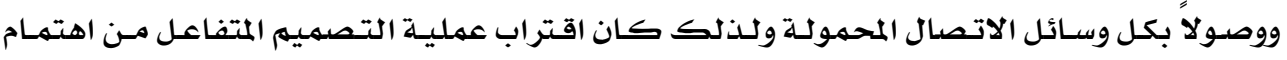

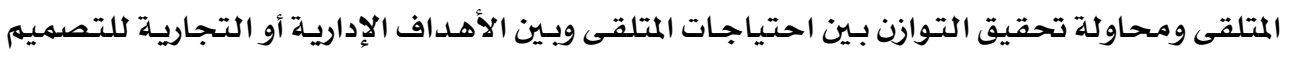

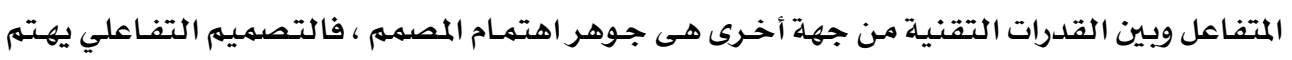

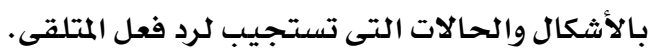
فالمفهوم الجديد لنجاح التصميم التفاعلى فى علاقته بالمتلقى يعتمد بشكل أساسى على :

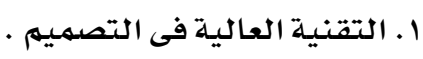

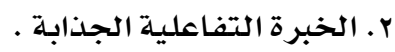

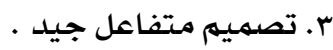

\section{ويتحقق ذلك من خلال ما يلى :}

ا ـ اتصال مؤثر عبر نظم تفاعلية وعملية

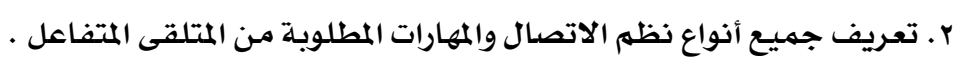

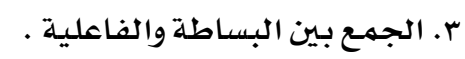

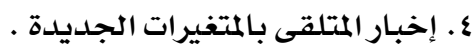

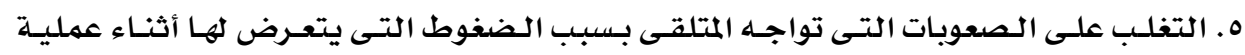
التفاعل.

وظيفـة التصميم التفـاعلي هى تحقيـق التـوازن بـين احتياجـات المستخدم مـن ناحيـة وبـين

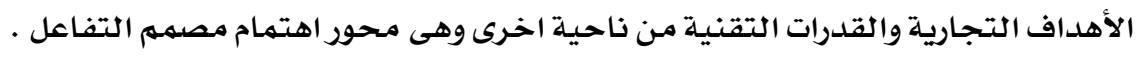

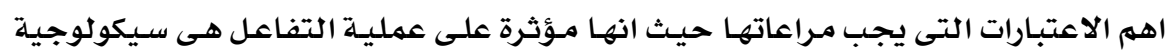

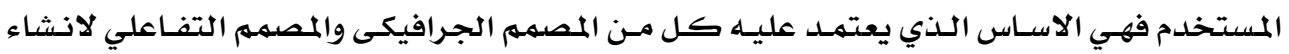
الواجهه .

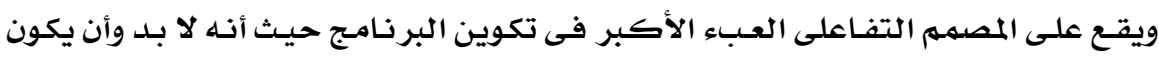

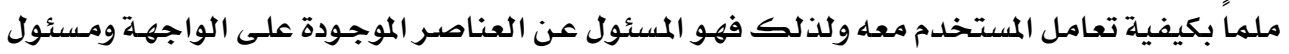

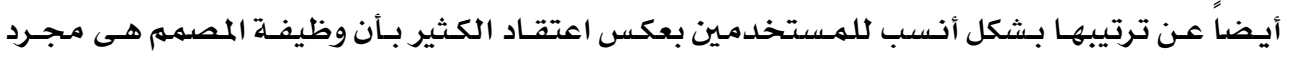

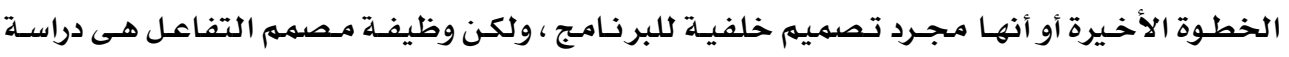




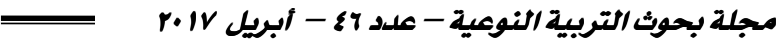

المستخدم دراسـة وافية ثم دراسـة البرنامج دراسـة وافية لكى يستطيع تصميهم واجهـة تفاعليـة للبرنامـج

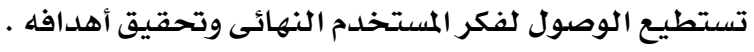
r. مفهوم التصميه الجرافيكى المتفاعل :

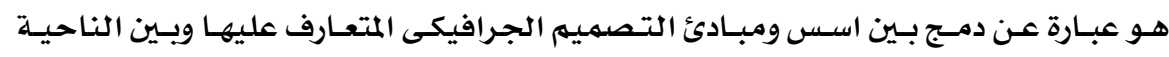

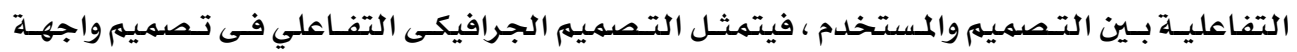

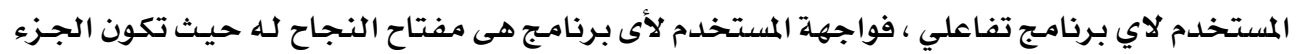

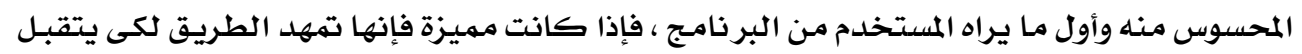

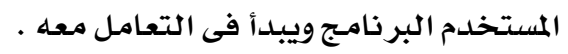

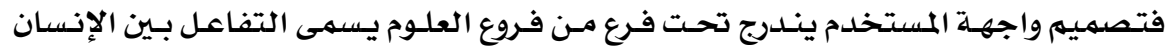

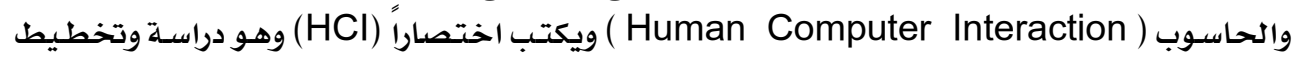

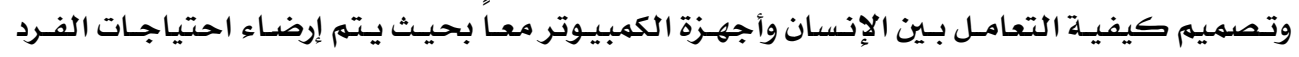
بطريقة فعالة .

تصميهم الواجهات ليس مجـرد صف لعناصـر التحكم فوق النمـاذج بطريقـة هندسية كمها

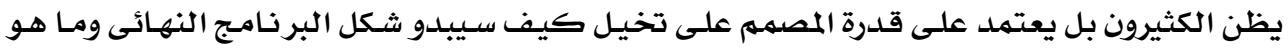

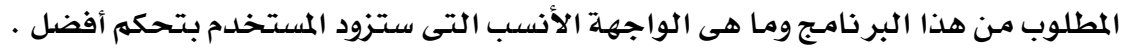

المكونات الرئيسية لواجهة المستخلم : • المدخلات :

الإدخال هو كيف يمكن لشخص أن يعمل على ادخال احتياجاته أو رغباته إلى الكمبيوتر. • المخرجات :

المخرجات فهى الطرق التى يحصل بها المستخدم على هدفه سواء مرئياً أو مسموعاً .

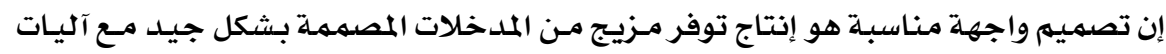

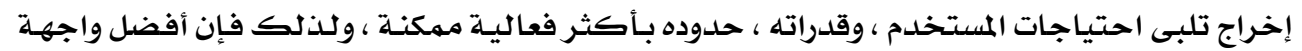

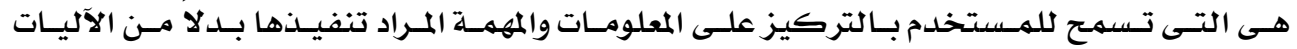

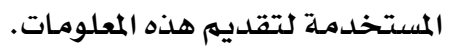

وتعتبر الخطوات التالية من وجهة نظري هى الأساس الذى يقوم عليه تصميم الواجهات التفاعلية: ا ـ الخلفية العلمية عن سيكولوجية المستخدم ومعرفة توجهاته وثقافته وتوقعاته من البر نامج.

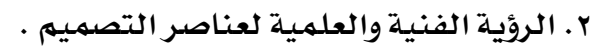
r. الأصالة والابتكار . 


\section{: ( Graphical User Interface): ماهية واجهة المستخدم الجرافيكية}

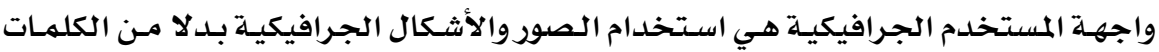

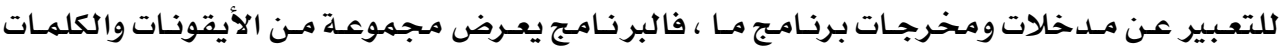

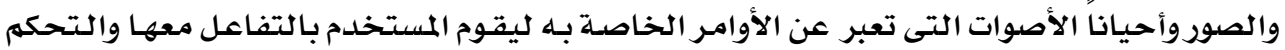
عن طريقها بالبر نامـج

\section{واجهة المستخدم الجرافيكية التفاعلية :}

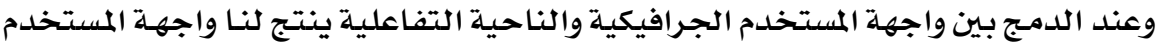

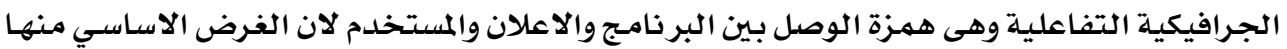

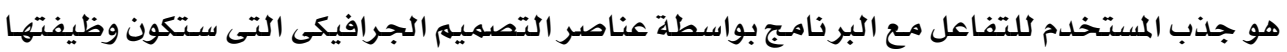

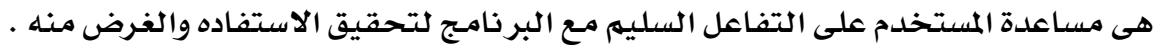

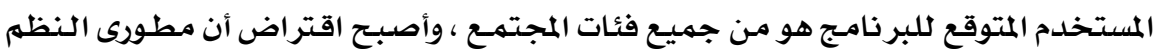

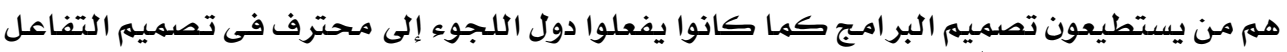

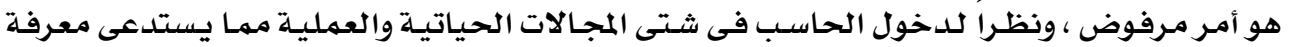

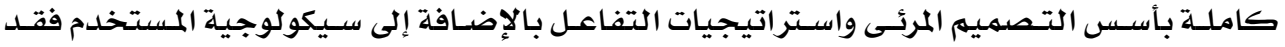

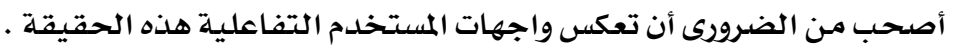

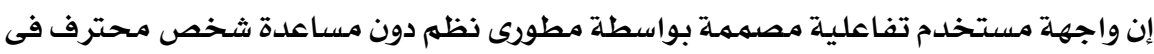

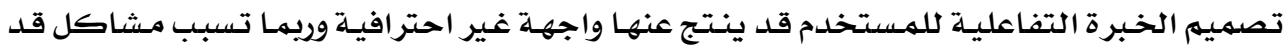

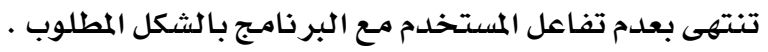

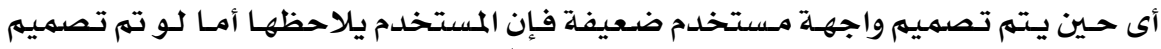

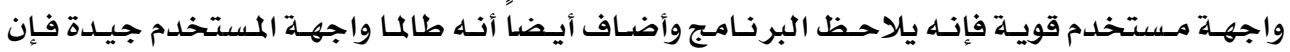

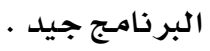

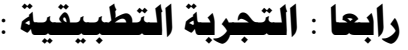

\section{مثال تطبيتي لتصميم لوحة اعلانية خارجية (Outdoor) تفاعلية للاعلان من براند سنتربوينت:}

مشكلة التجرية:

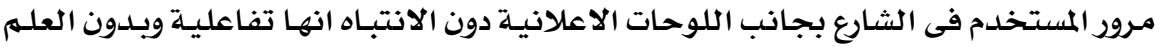

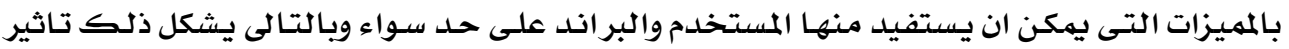

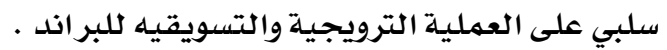
الفكرة والهدف من التجرية:

لفت نظر المستخدم وحثثه على محاولة التفاعل مـع الاعلان بأكثر من حاسـة من حواسـه . 


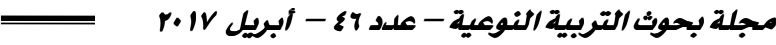

اسـتخدام التقنيـات فـى الهـاتف الـذكي لتحقيـق تجريـة اسـتخدام تفاعليـة بـين المستخلدم

والاعلان.

وصف التجرية :

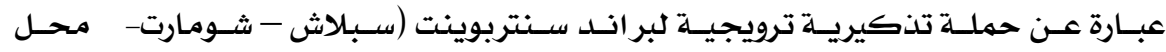

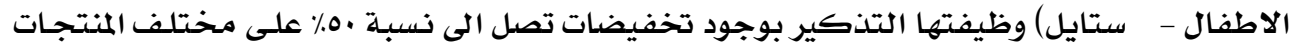
فى جميع افرع البر اند.

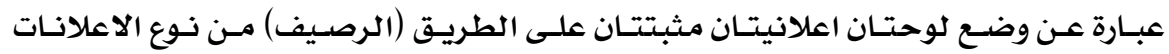

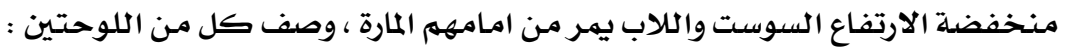

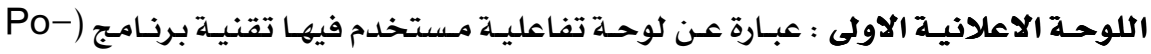

(motion

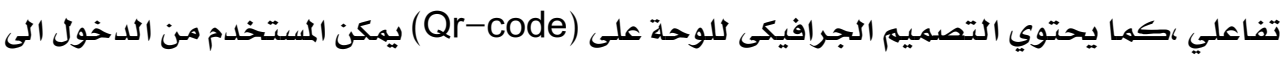

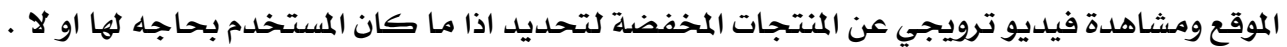
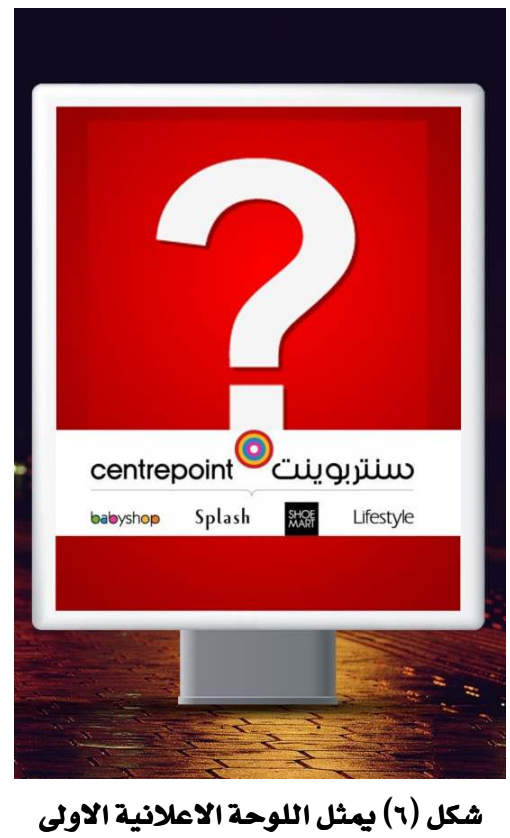

اللوحة الاعلانية الثانية : هى تحتوي على شاشلة تفاعلية باللمس تقدم للمستخدم واجهـهـ

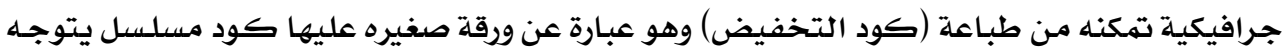

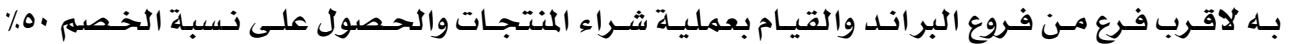
باستخدام هذا الكود. 


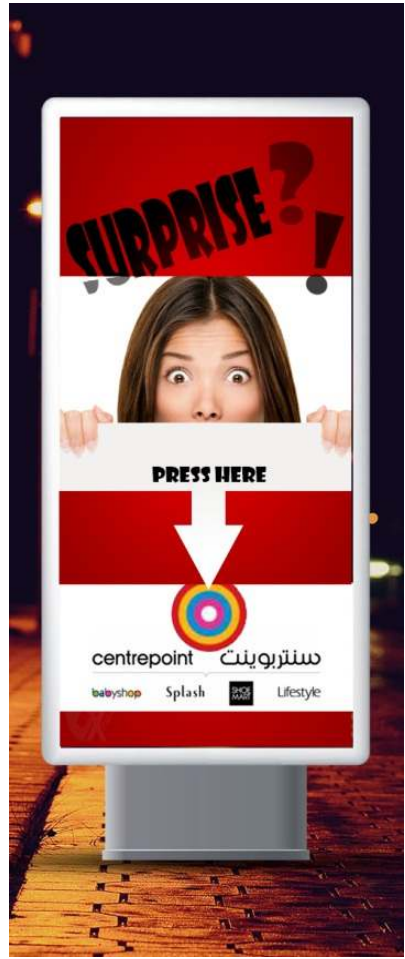

شكل (v) يمثل اللوحة الاعلانية الثانية

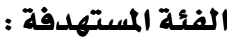

جميـع فئات المجتهمع من سن 17 الى سن +0.

الادوات المستخلدمة :

• لوحات اعلانية مثبته على الطريق من نوع الاعلانات منخفضة الارتفاع السوست واللاب .

• كاميرا حساسـة للحركة.

• جهاز عرض.

• لاب توب (كمبيوتر محمهول) .

البر امـج المستخدمة :

• برنامج photoshop 6c لعمل التصميمات الجرافيكية .

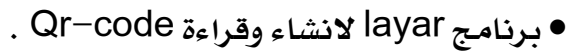

•برنامج Po-motion من برامج الحركة التفاعلية .

• برنامج App-makr برنامجة من برامج التطبيق الاعلانى . 


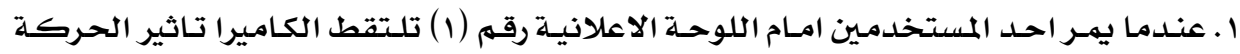

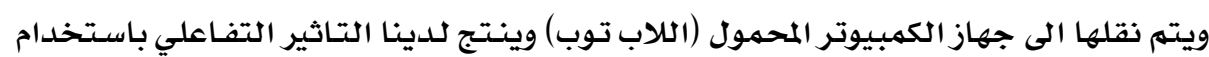

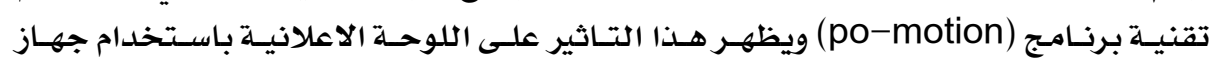

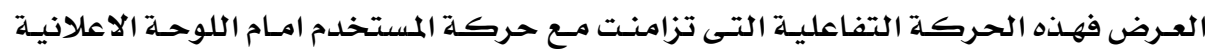

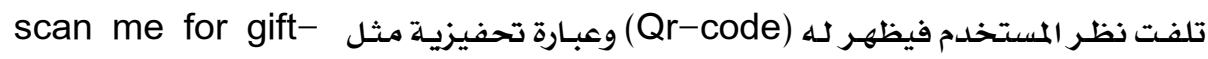

use layar app

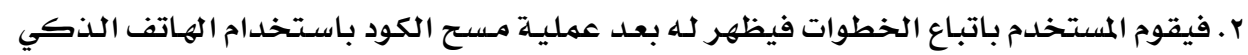

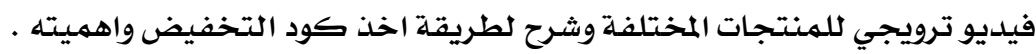

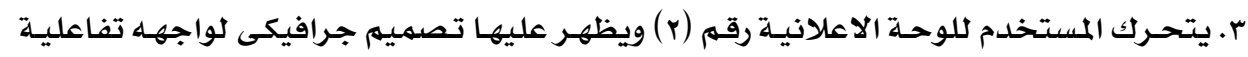

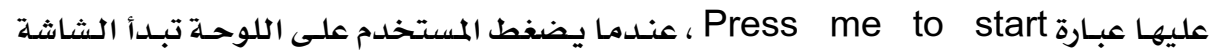

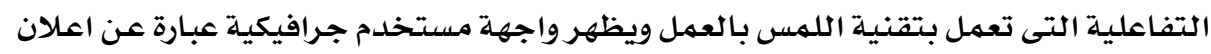

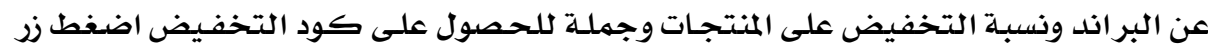
. press me to get your code

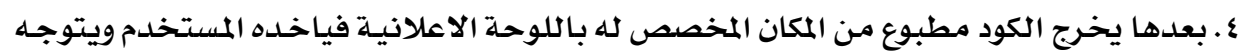

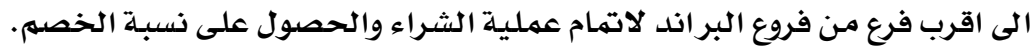

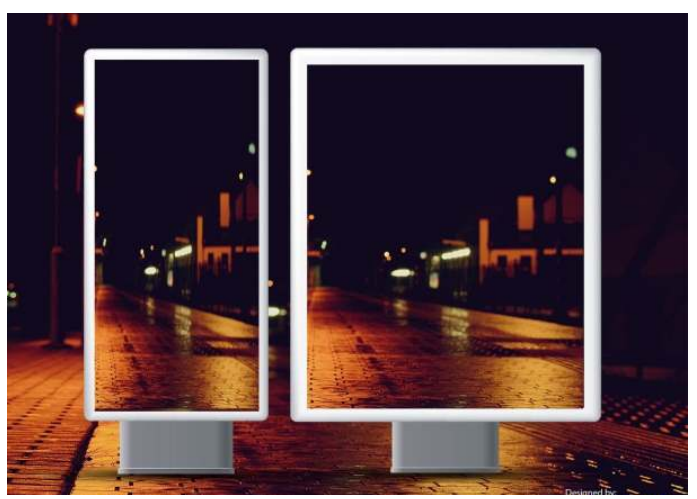
النماذج والصور : شكل (^) يمثل لوحتان (Outdoor) من النوع سوست ذات الارتفاع المنخفض مثبتتان على الطريق 


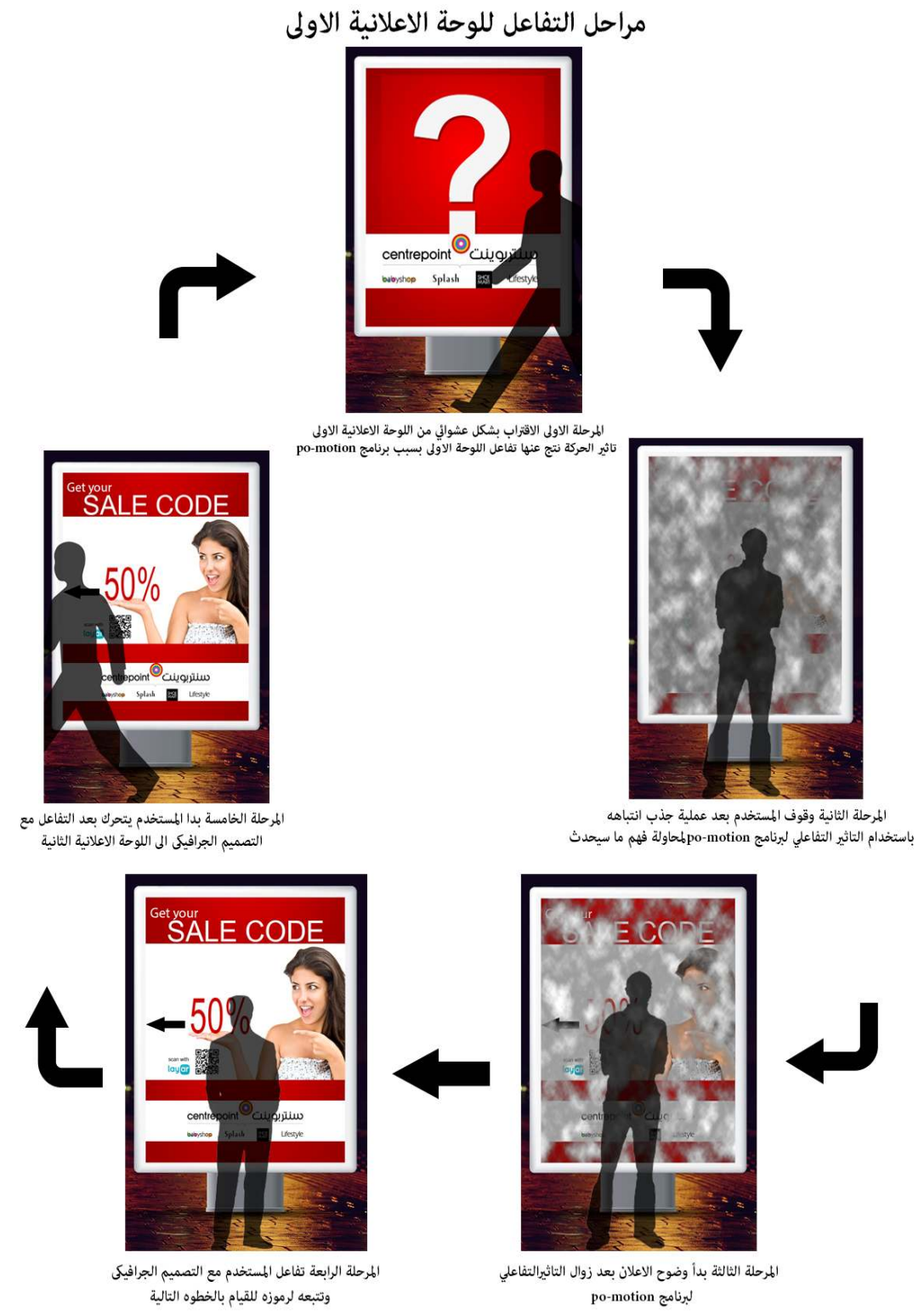

شكل (9) يمثل مراحل التفاعل للوحة الاعلانية الاولى 
مراحل التفاعل للوحة الاعلانية الثانية

المرحلة الاولى بعد توجه المستخدم من اللوحة الاعلانية الاولى المى هذه اللوحة

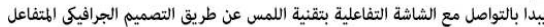
لاكتشاف المفاجاة وهى كود التخفيض

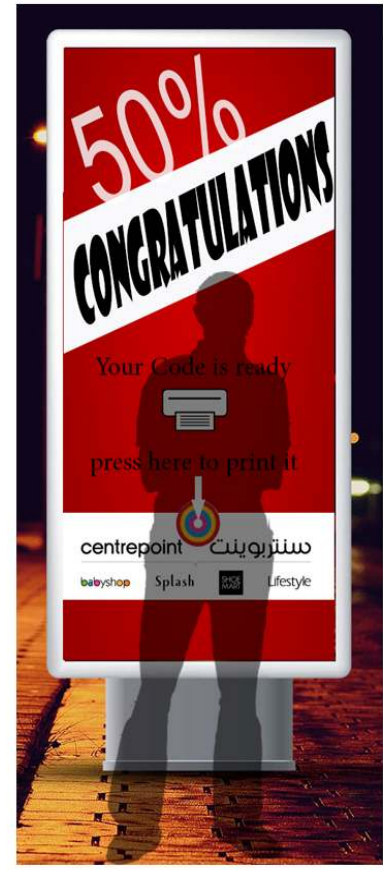

شكل (.1) يمثل مراحل التفاعل للوحة الاعلانية الثانية

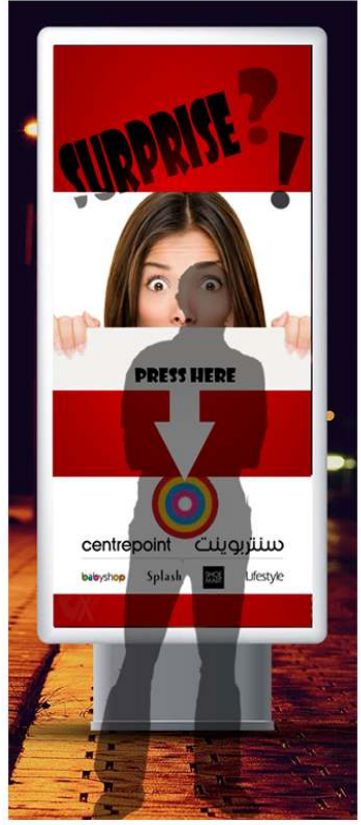

الهرحلة الثانية ادراك المستخدم للفكرة واتمام عملية التفاعل مع الاعلان بالضغط على زر استيلام كود التخفيض وبذلك تكون قد تمت تجربة المستخدم التفاعلية 
ا ـ التصميم التفاعلي الناجح جزء هام من نجاح العملية الاتصالية بين المستخدم والاعلان .

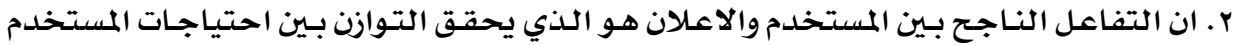

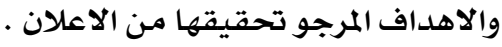

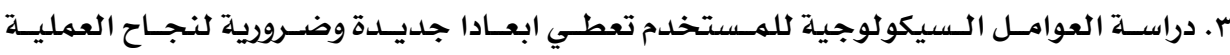

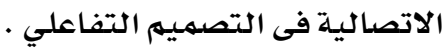

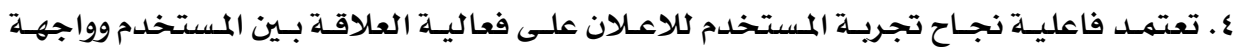

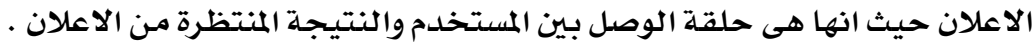

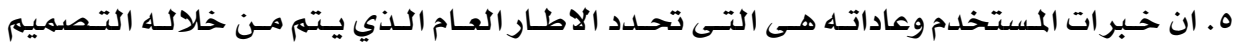

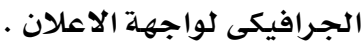

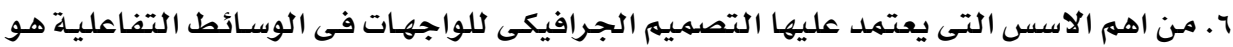

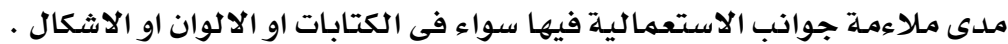
التتوصيات :

$$
\text { • الالمام الكامل بالهدف من البرنامج قبل البدء في تصميمسه . }
$$

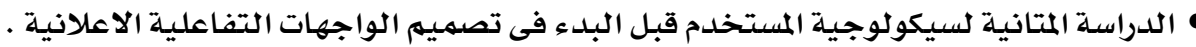

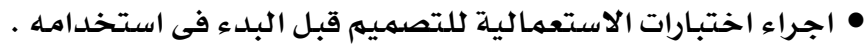

المراجع العربية والاجنبية :

ا. نرمـين على حسنى - البيئة التفاعلية فى الاعلان - رسـالة دكتوراه - كليـة الفنـون التطبيقية - جامعـة

$$
\text { حلوان - بسم الاعلان. }
$$

r. داليا محسن جابر علـوانى - التفكير الابداعي ودوره فى تصميهم الوسـائل الاعلانيـة غير النهطيـة - رسـالة

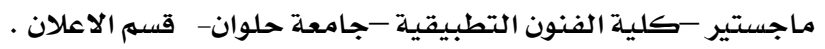

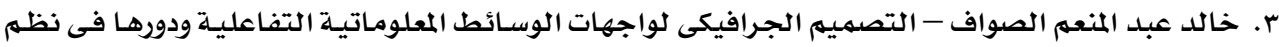

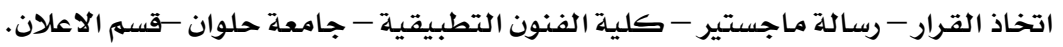

4. http://websitedesignadv.blogspot.com.eg/2014/03/outdoor.html

5. http://www.adcracker.com/techniques/Advertising_Techniques.htm

6. http://eman1437blogaddress.blogspot.com.eg/p/blog-page_36.html

7. https://www.maharah.net/courses/roah-mustafa-alem 
The Importance of Using Modern Technologies to Produce an Advertising with Interactive Graphic Design (For Example Applied to Outdoors Advertising)

\section{Abstract}

A few years ago the augmented reality was lunched effectively and connected with virtual reality .

The augmented reality is extension to virtual reality, it is one of most important techniques that merge the technique with the advertising by high efficiency to improve and develop the advertising filed.

And care for creating the advertising message by using the graphic design through attraction information agent by pointed procedures and is one of the best of method to meet the user's needs To support the advertising idea and achieve good and strong communication between the customer and the product or service that is advertising subject. the most important technique used in augmented reality which used in advertising filed is QR code and Interactive screens that used the technique programs because it support the interfacing between the user and the product like layer program, augment program and po_motion program because it easy to use and support the connection between the user and product and adding value to the advertising and changing from $2 \mathrm{D}$ advertising to $3 \mathrm{D}$ advertising , the interfacing will be in the same time of virtual interfacing.

As graphic designer, my choice is merging between, augmented reality technique and advertising (indoor and outdoor advertising) the augmented reality allow to the user to see the real world around him.

This technique is providing strong communication between the user and product by clear information with ability of interaction in interring and outing data by easy and efficiency method.

Finally interaction graphic design is the communication ring between the augmented reality technique and the required customers. The user can give us feedback come from his interfacing with the advertising .the feedback let us to develop and improve from interaction side, and guide us to acceptance of the customer to this advertising. 